\title{
СОЦАЛЬНІ КОМУНІКАЦІї
}

\author{
УДК 378:070
}

DOI: $10.15587 / 2313-8416.2019 .168893$

\section{КОМПЕТЕНТНОСТНЫЙ ПОДХОД К ФОРМИРОВАНИЮ СОВРЕМЕННОГО ЖУРНАЛИСТА В УСЛОВИЯХ МОДЕРНИЗАЦИИ ОБРАЗОВАНИЯ}

\author{
() Ю. Н. Радченко, В. М. Маренич
}

Проанализирован процесс формирования современного журналиста. Выявлена сущность компетентностного подхода к профессиональной подготовке журналистов в условиях модернизации образования. Очерчены наиболее важные пути формирования профессиональных навыков журналистов в процессе журналистского образования, ориентированного на успех. Раскрыта неразрывная связь познавательного, практического и аксиологического компонентов в системе журналистского образования, свидетельствующая о соответствии сложивщейся практики подготовки журналистов современной парадигме образования

Ключевые слова: компетентностный подход, современный журналист, модернизация образования, компетенция, компетентность, духовная культура

\section{1. Введение}

В современном информационном обществе в условиях модернизации системы профессионального образования изменилась роль журналистики и журналиста. Возникает вопрос - нужно ли журналисту профессиональное образование и каким оно должно быть? Каким образом современный журналист может проявить свой талант и творческий потенциал.

Все это потребовало пересмотра содержания и подхода к организации журналистского образования в Украине. К тому же в подготовке журналистов в Украине за последнее десятилетие мало что изменилось. Журналистское образование должно быть направлено не просто на формирование конкурентоспособного специалиста, но и успешной личности. Журналисты должны быть компетентными, порядочными личностями, духовно богатыми, честными перед собой и своим народом.

Вырисовывается и общественная роль журналиста - быть носителем общественных ценностей, общественной морали [1].

\section{2. Литературный обзор}

Проанализируем взгляды некоторых авторов по вопросу компетентностного подхода к формированию современного журналиста. Ученые [2, 3] отмечают, что в связи с изменением роли журналиста и журналистики в современном обществе и процессов модернизации системы профессионального образования, возникла необходимость пересмотра содержа- ния и подхода к организации журналистского образования в Украине.

Не стихает дискуссия о том, нужно ли журналисту профессиональное образование и каким должен быть современный журналист $[4,5]$.

Ряд авторов [6, 7] отстаивает идею журналистского образования путем развития университетской системы подготовки журналистских кадров. Именно университеты обучают интеллектуальным профессиям и готовят будущих исследователей, развивают науку и учат познавать. Эти две задачи являются определяющими в деятельности университетов на протяжении всей истории их существования. Профессионализм, умение вести исследование, познание, высокая культура - эти вещи должны объединить в себе университетские программы.

Журналист, как утверждают зарубежные авторы [8] должен уметь глубоко проникать в жизнь, иметь высокую профессиональную культуру, обладать искусством журналистского письма. А в процессе их обучения применять рефлективный подход [8]. Высшие школы на сегодняшний день должны выбирать целеустремленных абитуриентов со школ [9].

Таким образом, необходимо применение компетентностного подхода в журналистском образовании, направленном не просто на формирование конкурентоспособного специалиста, но и успешной личности. Эта проблема чрезвычайно актуальна в условиях модернизации образования и требует дальнейшей разработки учеными. 


\section{3. Цель и задачи исследования}

Цель статьи - исследование сущности компетентностного подхода в процессе формирования современного журналиста и модернизации образования.

Для достижения цели были поставлены следующие задачи:

1. Проанализировать процесс формирования современного журналиста.

2. Выявить сущность компетентностного подхода к профессиональной подготовке журналистов в условиях модернизации образования.

3. Очертить наиболее важные пути формирования профессиональных навыков журналистов в процессе журналистского образования, ориентированного на успех.

4. Компетентностный подход в журналистском образовании в условиях его модернизации

Журналистскому образованию в Украине уже более 100 лет, но оно продолжает оставаться в центре внимания представителей высшей школы, медиаиндустрии, журналистского сообщества, общественности. Не стихает дискуссия о том нужно ли журналисту профессиональное образование, чему и как учить будущих специалистов [10-12].

Причина такого интереса, в поиске обществом адекватного современности понимания профессии журналиста, природы СМИ, развитие цифровых технологий, трансформации ценностных и этических установок в журналистике [13].

Сущность современного этапа развития национального профессионального образования выражается идеей модернизации. Модернизация образования направлена на его обновление, путем приведения характеристик и качеств уже сложившейся системы образования в соответствие с современными требованиями. Сегодня проблемы модернизации приобретают все новые аспекты, требующие дальнейшего осмысления. Изменение роли журналистики и журналиста в современном обществе, с одной стороны, и процессы модернизации системы профессионального образования, с другой, потребовали пересмотра содержания и подхода к организации журналистского образования. Согласно Болонской конвенции в сфере образования произошли серьезные преобразования. Возникла необходимость в государственных образовательных стандартах по проблемам высшей школы, в которых компетентностный подход был заявлен как доминанта образовательного процесса [7].

Основная задача реализации компетентностного подхода состоит в том, чтобы создать социально-мобильного специалиста, способного достаточно легко передвигаться как в горизонтальной, так и в вертикальной общественной системе [14], адаптироваться к работе в быстро меняющихся жизненных ситуациях [7], конкурентоспособного, умеющего отходить от сложившихся стереотипов и предлагать новые технологии решения профессиональных задач [4]. Современная рыночная система дает толчок для проявления и развития индивидуальности человека и его конкурентоспособности.
Но конкурентоспособный - не значит «успешно проданный» и не как существо, в котором в борьбе за «счастье быть проданным», преобладают эгоистические стремления [14]. Быть конкурентоспособным - это значит не потерять уникальные свойства и человеческие достоинства личности, не быть продажным относительно себя и своего народа [1].

Журналист, который не любит своего народа, не может быть по отношению к нему объективным, не может говорить той правды, которую говорят с любовью к людям [1]. Потому ненациональная и негосударственная позиция журналиста очень часто подрывают его профессиональную репутацию. В сочетании с агрессивностью медиа-среды мы иногда получаем журналистов, которых сравнивают со «стервятниками» на информационном поле.

Следует согласиться с теми, кто считает, что такие журналисты начинают «питаться падалью, скандалами, кровью и т.д.». Когда такой журналист начинает не просто искать скандалы, а провоцировать и создавать их - он «превращается из стервятника в хищника» [15]. Мы считаем, бороться с этим явлением надо только одним - повышением уровня общего и профессионального образования, качественной подготовкой журналистских кадров. Которые не только и не столько по закону, а по совести будут просто брезговать заниматься подобного рода «хищничеством», то есть «желтой журналистикой» [15].

Журналистское образование должно быть направлено не просто на формирование конкурентоспособного специалиста, а на формирование успешной личности. Успех является формой самореализации человека, ориентированного на достижения. Успех определяется тем, насколько правильно человек определил смысл своей жизни, свое предназначение и выполнил, осуществил их.

У журналистики нет другой миссии в обществе, кроме как служить своему народу через его правдивое информирование, защищая тем самым интересы людей, их традиции, способ жизни, их культуру. Настоящая журналистика не может быть не национально творческой, потому что она будет против того народа, которому якобы служит. Логично встает вопрос: какого народа журналистика и чьи интересы она проповедует?

Общественная миссия журнализма очевидна, если иметь в виду общественные медиа. В этом контексте вырисовывается фигура и общественная роль журналиста - быть носителем общественных ценностей, общественной морали [1]. Классические университеты являются национальной интеллектуальной гордостью, интеллектуальной совестью государства [6]. Именно такие университеты способны формировать национально сознательные интеллектуальные личности.

Другими словами, перед честным журналистом всегда стоит вопрос компетентности, умение анализировать, мужества и высокой нравственности. не случайно во всем мире доминирующей стала университетская система образования журналистов, хотя она не лишена определенных недостатков, если речь идет о подготовке именно работников массмедиа [6]. 
В некоторых зарубежных странах предлагается даже руководство к обучению журналистского письма [8] через рефлективный подход к обучению журналистов [16], выбирая целеустремленных абитуриентов со школы [9].

Образование призвано помочь человеку осознать критерии, на основе которых он строит свое поведение. Определяя парадигму современного образования Л. А. Беляева подчеркивает, что сегодня необходим не просто человек знающий (познавательный компонент), умеющий (прагматический компонент), но и человек понимающий, способный к самореализации, самостоятельному выбору ценностей и смыслов своего существования (аксиологический компонент), а также человек компетентный, умеющий применять свои знания, умения и ценности для решения личностных, социальных и профессиональных задач. Именно такая парадигма обеспечивает жизненный успех личности [2].

Был проведен анализ научных и методических статей, обобщающих накопленный опыт подготовки журналистов с целью определить насколько соответствует система профессиональной подготовки журналистов в учреждениях высшего образования, современной парадигме образования, ориентированной на формирование успешной личности. Она включает в себя познавательный, прагматический и аксиологический компоненты. В ходе анализа выяснили, что ни у кого не вызывает сомнения необходимость фундаментальной теоретической подготовки журналистов. Отмечается, что современному журналисту нужны широкие гуманитарные знания в области мировой литературы, социологии, политологии, экономики, психологии, биологии, культурологи. Если говорить о формировании и анализе повестки дня как ключевой функции современной журналистики, то именно широкое гуманитарное и социально-политическое образование помогает журналистам выявлять информационные приоритеты, откладывая в сторону менее значимые новости.

Сложность мира вокруг СМИ, редакций, журналистов и потребность объективного осмысления глубинных процессов в обществе не позволяет в процессе подготовки журналистов отказаться от направления на качественное гуманитарное образование [13]. При этом подчеркивается, что широкое гуманитарное знание не является самоцелью журналистского образования, это основа для формирования профессиональных навыков. Особое внимание уделяется психологической подготовке, развитию коммуникативных способностей студентов [10], а также практических навыков подготовки журналистских материалов для различных СМИ с использованием современных информационных технологий [17].

Профессиональные навыки формируются как в ходе учебного процесса, так и в ходе практики $[4,13$, 17]. Уделяется внимание формированию гражданской позиции будущих журналистов [10], их профессиональной культуре [12], социально-профессиональной компетенции [3]. «У студентов уже в период обучения в университете складывается ценностно окрашенное отношение к будущей профессии: она воспринимается как общественно значимая творче- ская профессия, в которой востребованы специалисты, обладающие высоким культурно-ценностным потенциалом, творческой индивидуальностью, способные вносит свой вклад в развитие современной журналистики» [11].

Чтобы быть в полном смысле журналистом нужно сочетать в себе элементы гражданского самосознания и профессиональных навыков редакционной работы. Без «гражданского» элемента журналист являет собой профессионала-коммуникатора, способного распознать запросы аудитории, донести до нее свое сообщение и получить искомую обратную связь. Без журналистского профессионализма он представляет гражданского активиста, неспособного доходчиво и результативно общаться с массовыми аудиториями [10].

Мы разделяем точку зрения тех, кто считает, что широкие энциклопедические знания в сочетании с навыками журналистского ремесла не гарантируют успеха в журналистской деятельности. Третьим и необходимым слагаемым журналистского искусства является духовная культура. Компоненты духовной культуры педагога выделены и описаны профессором Е. И. Артамоновой. Исходя из этого, можно выделить компоненты духовной культуры журналиста, которые иллюстрируют интегративные личностные образования, такие как: концепция профессиональной жизни, профессиональная картина мира, профессиональная позиция и индивидуальный стиль духовности.

Таким образом, мы можем констатировать неразрывную связь познавательного, прагматического и аксиологического компонентов в системе журналистского образования, что свидетельствует о соответствии, в целом, сложившейся практики подготовки журналистов в современной системе образования, ориентированной на успех. Признавая важность аксиологического компонента профессиональной подготовки, акцент все же делается на прагматическом компоненте, на практико-ориентированном подходе к подготовке будущих журналистов.

Был проведен анализ работы военных журналистов. У многих из них нет практического опыта, поэтому они должны прислушиваться к вопросам которые ставят люди. Оружие всегда вызывало повышенный интерес. Тема оружия и перевооружения тесно связана с базовыми людскими стремлениями. Мы должны быть лучшими в жесткой конкурентной борьбе. Быть сильнее других. Успех оружия - это и успех страны. Военные журналисты не делают оружия, но они заинтересованы в главном - в своевременном и взвешенном освещении процессов и усилий, которые делают нашу страну не только сильнее, но и умнее. В этом и есть главная сила. Ведь для Вооруженных сил Украины создается все самое лучшее [18].

Образцом порядочности и компетентности такого журналиста является главный редактор журнала «Defense Express»Сергей Згурец [19], который на страницах своего журнала [8] постоянно подымает тему оружия, которая тесно связана с базовыми людскими стремлениями. Быть лучшими в жесткой конкурентной борьбе, быть сильнее других, ведь успех оружия - это и успех страны. Военные журналисты должны быть компетентными в военном современном арсенале. Он лично просто ведет беседы как это 
оружие создавалось, как оно выглядит и как оно работает. Проводит также журналистское расследование по формированию и перевооружению различных родов войск в Украине. Не только вещая, он еще описывает это. Журнал является авторитетным изданием в Украине, который решает вопросы не только формирования и перевооружения украинской армии, но и затрагивает социальные вопросы, например, строительство жилья для военнослужащих.

В начале 2000-х годов в Украине были разработаны проекты образцов новой военной техники, которая известна у военных кругах - автоматизированная система боевого правления (АСБУ), способна решать задачи тактической группы кораблей. Журналисты должны быть специалистами (военными в нашем случае), чтобы помочь своими статьями широкому кругу читателей понять, что использование военной элементной базы оправдано тем, что на сегодняшний день государственное предприятие «НИИ «Квант»»» решает 99 \% всех задач, касающихся создания АСБУ, самостоятельно [18]. Привлечение сторонних специалистов требуется только для решения задачи сопряжения системы с вооружениями, которые будут установлены на корабле [18].

Журналисту удалось вникнуть в проблему и довести, что использование иностранной элементной базы также оправдано [18]. Во-первых, для создания перспективного корвета, которым будет украинский корабль, нужно использовать самые передовые технические решения. Во-вторых, к сожалению, возможности в области микроэлектроники, которых смогли добиться советская наука и производство, были безвозвратно утрачены с развалом СССР по причине разрыва кооперационных связей. В-третьих, нет необходимости изобретать самостоятельно элементную базу, а эффективнее использовать продукцию мировых лидеров, в несколько раз преумножая потенциал лучшей в мире элементной базы благодаря высокому научному потенциалу наших ученых и инженеров. Но без импортной элементной базы задача построения современных систем боевого управления не может быть решена [18].

Читая беседу журналиста Згурец Сергея о работе ГП «НИИ «Квант» понимаешь, что оно руководствуется основным принципом: «Для Вооруженных сил Украины создается все самое лучшее, для инозаказчиков - в рамках технического задания» [18], что такое предприятие имеет все необходимые структурные и научные наработки для разных форм сотрудничества, от разработок до прямых поставок изделий, с учетом всех требований международных стандартов. ГП «НИИ «Квант», имея бессрочную государственную лицензию на создание, ремонт и модернизацию военной техники, постоянно расширяет сферы военно-технического сотрудничества с зарубежными странами. ГП «НИИ «Квант», успешно выполняет контракты со странами на разных континентах: с Индией, Италией, Казахстаном, КНР, Мьянмой, Пакистаном, Кореей, Польшей, Сингапуром, Швейцарией и др. странами [18].

Над созданием программного обеспечения проектируемых систем этого предприятия работают лучшие математики страны, в частности, из числа одаренной молодежи [18]. Благодаря этому заказчики уверены, что ГП «НИИ «Квант» находится на острие современных научных достижений.

Основу коллектива предприятия все же составляют люди пенсионного возраста [18]. Поэтому самой большой задачей для руководства предприятия является привлечь и, главное, удержать молодежь, создавая для молодых специалистов необходимые условия, как например, обеспечение достойной стабильной заработной платы, привлечение к решению сложных задач. А это тоже одна из сильных мотиваций [18].

Таким образом, украинские журналисты подымают вопросы как привлечь и, самое главное, удержать молодежь в Украине. Она не должна уезжать за границу, важно привлекать молодых квалифицированных и компетентных военных специалистов к развитию военной техники на Украине, создавая для них все необходимые условия [18].

Чтобы быть на острие военных вопросов украинские журналисты часто принимают непосредственное участие в работе международных авиационных салонов [20, 21]. Работу авиакосмического форума освещали 1735 международных и региональных средств массовой информации. Выставка стран Персидского залива в 2013 г. стала рекордной для авиасалонов в Дубае по количеству официальных государственных делегаций, среди которых не последнее место занимала украинская [20]. Журналисты освещали обстоятельно основные особенности и достижения выставки, а также тенденции развития авиационного рынка стран Персидского залива. На выставке был представлен весь спектр продукции по авиационной тематике гражданского и военного назначения [20, 21].

Особенно важная работа журналистов заключается в том, чтобы советуясь со специалистами, описывать достижение оборонных комплексов в миpe. Среди оборонных экспозиций выставки наиболее мощно были представлены направления многофункциональных истребителей и беспилотных авиационных комплексов.

На этом непростом рынке журналисты редко пишут о качестве продукции, но отмечают всегда уровень выставок, салонов [20, 21]. Подчеркивают, что на выставках такого рода присутствуют фактически все ведущие мировые игроки в авиационном сегменте [22]. Они представляют для Украины интерес по широкому спектру вопросов - от развития технологий до механизмов продвижения своей продукции на международные рынки.

Речь идет, в том числе, и об алгоритмах выхода на один из наиболее крупных и специфических рынков Объединенных Арабских Эмиратов и других стран региона. Конечно, в этом направлении Украина, в силу объективных причин, находится в начале пути [22].

\section{5. Результаты исследования}

Результатами исследования является определение основных компетентностных подходов к формированию современного журналиста в условиях модернизации образования, а именно: 
- изменением общественной роли современного журналиста, он должен быть носителем общественных ценностей, общественной морали, а также умением глубоко проникать в жизнь, иметь высокую профессиональную культуру.

- потребностью пересмотра содержания и подхода к организации журналистского образования, которое должно быть направлено в условиях его модернизации на качественную профессиональную подготовку;

- неразрывной связью познавательного, прагматического и аксиологического компонентов в системе журналистского образования;

- совершенствованием и развитием интеллектуального и профессионального потенциала студента-журналиста, усилением процессов гуманизации и гуманитаризации его образования.

В рамках каждого направления определены основные группы мероприятий, реализация которых приведет к достижению поставленных целей.

\section{6. Выводы}

1. В условиях модернизации образования изменилась роль современного журналиста как носителя общественных ценностей, общественной морали. В связи с этими изменениями он должен уметь глубоко проникать в жизнь, иметь высокую профессиональную культуру, быть компетентным, мужественным, высоконравственным и честным.
2. Исследованы основные компетентностные подходы к формированию современного журналиста в условиях модернизации образования. При этом возникла потребность и необходимость пересмотра содержания и подхода к организации журналистского образования в Украине, которое в условиях его модернизации должно быть направлено на качественную, компетентную и профессиональную подготовку журналиста.

3. Обоснована идея журналистского образования путем развития университетской системы подготовки журналистов, которая обучает интеллектуальным профессиям и готовит будущих исследователей, развивает науку и учит познавать. Эти задачи являются определяющими в деятельности университетов. Университетские программы должны объединить в себе: профессионализм, умение вести исследование, познание, высокую культуру, конкурентоспособность. Они должны быть направлены не просто на формирование конкурентоспособного специалиста, но и успешной личности, включающей в себя познавательный, прагматический и аксиологический компоненты.

Реализация этих направлений компетентностного подхода обеспечит формирование современного журналиста, который будет служить своему народу через его правдивое информирование, защищая тем самым интересы людей, их традиции, способ жизни, их культуру.

\section{Литература}

1. Різун В. В. Ідея журналістської освіти в контексті дискурсу про університет: міжнар. наук. конф. // Ідея університету: сучасний дискурс. Київ, 2011. С. 37-38.

2. Беляева Л. А. Успех как цель и ценность образования: сб. науч. тр. // Понятийный аппарат педагогики и образования. 2010. № 6. С. 184-191.

3. Интеграция научных дисциплин в журналистском образовании: монография / Александров Л. Г., Артишевская Т. М., Загидуллина М. В. и др.; ред. Загидуллина М. В., Фатеевой И. А. Челябинск: Челяб. гос. ун-т., 2007. 230 с.

4. Прозоров В. В. Ненасытная профессия (как сочетать в образовательном процессе два ключевых глагола - «учить» и «учиться»? / ред. Лазутина Г. В. // Современное журналистское образование: компетентностный подход. Москва: МедиаМир, 2011. С. 213-223.

5. Ушакова Н. В. Проблемы разработки программ подготовки журналистов на основе государственных образовательных стандартов третьего поколения / ред. Лазутина Г. В. // Современное журналистское образование: компетентностный подход. Москва: МедиаМир, 2011. С. 92-94.

6. Ідея Університету: Антологія / ред. Зубрицька М. Львів: Літопис, 2002. С. 21.

7. Распопова С. С. Достичь компетентности, чтобы формировать компетенции (два ракурса компетентностного подхода) / ред. Лазутина Г. В. // Современное журналистское образование: компетентностный подход. Москва: МедиаМир, 2011. С. $13-19$.

8. Paglinawan W. M. C. Journalistic Writing Competencies of AB Communication Students: Basis for Development of Training Manual in Journalism // Global Media Journal. 2018. Vol. 16, Issue 31. P. 144.

9. Aporbo R. Course of Study in Journalism. Manila: Division of City Schools, 2015.

10. Корнев M. C. Understanding journalism: что такое «журналистика» в современном цифровом пространстве? // Журналист. Социальные коммуникации. 2014. № 4. С. 20-27.

11. Кустов Ю. А., Исакова Т. Б. Самостоятельная работа как средство формирования социально-профессиональной компетентности личности: сб. науч. тр. // Понятийный аппарат педагогики и образования. 2012. № 7. С. 351-361.

12. Саблина Т. А. Актуализация субъективной позиции как фактор развития профессиональной культуры студентажурналиста / ред. Лазутина Г. В. // Современное журналистское образование: компетентностный подход. Москва: МедиаМир, 2011. С. 25-32. $2011.96 \mathrm{c}$.

13. Вартанова Е., Ажгихина М. Диалоги о журналистике. Москва: Фак. журналистики МГУ им. М. В. Ломоносова,

14. Бенин В. Л., Фролов О. В. Культурная составляющая компетентностного подхода: сб. науч. тр. // Понятийный аппарат педагогики и образования. 2012. № 7. С. 117-125.

15. Тихомиров В. А. Главным мерилом пригодности к журналистике становится ... рубль // Журналист. Социальные коммуникации. 2014. № 4. С. 77-82.

16. Sheridan Burns L. A reflective approach to teaching journalism // Art, Design \& Communication in Higher Education. 2004. Vol. 3, Issue 1. P. 5-16. doi: http://doi.org/10.1386/adch.3.1.5/0 
17. Шестеркина Л. П., Белова Л. И. К «идеальному» журналисту - через студенческую практику (методическое эссе) // Журналист. Социальные коммуникации. 2014. № 4. С. 83-103.

18. Радченко Ю. Для Вооруженных сил Украины создается все самое лучшее, для инозаказчиков - в рамках технического задания // Defense Express. 2014. № 1. С. 6-13

19. Згурець С. О планах // Defense Express. 2014. № 1. С. 1

20. Самусь М. В. В фокусе - главный авиационный форум Персидского залива // Defense Express. 2014. № 1. С. $21-29$.

21. Копчак В. Украинский срез // Defense Express. 2014. № 1. С. 31-33.

22. Неботов П. На этом непростом для нас рынке можно и нужно работать // Defense Express. 2014. № 1. C. 34-36.

Рекомендовано до публикации д-р пед. наук, професор Щебликіна Т. А. Дата надходження рукопису 30.04.2019

Радченко Юрий Николаевич, кандидат экономических наук, профессор, Харьковский торговоэкономический колледж Киевского национального торгово-экономического университета, ул. Клочковская, 202, г. Харьков, Украина, 61045

E-mail: kharkov@htek.com.ua

Маренич Виктория Михайловна, кандидат юридических наук, доцент, кафедра журналистики и рекламы, Харьковский торгово-экономический колледж Киевского национального торгово-экономического университета, ул. Клочковская, 202, г. Харьков, Украина, 61045

E-mail: kharkov@htek.com.ua 